\title{
Youth Services System Review: Moving From Knowledge Gathering to Implementation Through Collaboration, Youth Engagement, and Exploring Local Community Needs
}

\author{
E. B. Brownlie and Gloria Chaim \\ Centre for Addiction and Mental Health and University of Toronto \\ Olivia Heffernan and Tyson Herzog \\ Centre for Addiction and Mental Health \\ Joanna Henderson \\ Centre for Addiction and Mental Health and University of Toronto
}

E. B. Brownlie, Margaret and Wallace McCain Centre for Child, Youth and Family Mental Health, Centre for Addiction and Mental Health, and Department of Psychiatry, University of Toronto; Gloria Chaim, Margaret and Wallace McCain Centre for Child, Youth and Family Mental Health, Centre for Addiction and Mental Health, and Department of Psychiatry, University of Toronto; Olivia Heffernan, Margaret and Wallace McCain Centre for Child, Youth and Family Mental Health, Centre for Addiction and Mental Health; Tyson Herzog, Margaret and Wallace McCain Centre for Child, Youth and Family Mental Health, Centre for Addiction and Mental Health; Joanna Henderson, Margaret and Wallace McCain Centre for Child, Youth and Family Mental Health, Centre for Addiction and Mental Health, and Department of Psychiatry, University of Toronto.

This project was funded by Health Canada Drug Treatment Funding Program in cooperation with the Ontario Ministry of Health and Long-Term Care. We express our sincere gratitude to the youth, service providers, family members, and other supporters of youth who participated in this project, as well as the advisory networks and agencies that helped make the project possible. We would also like to thank Megan Barker, Erica Suh, Dave Summers, and other members of the YSSR project team. Finally, we thank Josina Vink for the design of the ecosystem maps and Christa Orchard and Lisa Hawke for their assistance in the preparation of this manuscript.

Correspondence concerning this article should be addressed to E. B. Brownlie, Child, Youth and Emerging Adult Service Centre for Addiction and Mental Health, 80 Workman Way, Toronto, ON M6J 1H4; (416) 535-8501, ext. 34062. Email: eb.brownlie@ utoronto.ca 


\begin{abstract}
This article describes a two-phase, multi-sectoral project aimed at enhancing youth services addressing substance use in Ontario. In the information gathering phase, a youth-focused website and survey, focus groups, and interviews were used to elicit perspectives from multiple stakeholders. In the implementation phase, capacity-building and consultations on transition-aged youth needs were conducted to inform youth transition-readiness checklists. We discuss the importance of engaging youth as collaborators as well as respondents and the processes used to tailor findings to local contexts for implementation.
\end{abstract}

Keywords: substance use, service system, youth engagement, cross-sectoral collaboration, health equity, knowledge exchange

\title{
RÉSUMÉ
}

Cet article décrit un projet multisectoriel à deux volets qui vise à améliorer les services de toxicomanie pour les jeunes Ontariens. Premièrement, un site web et un sondage axés sur les jeunes, des groupes de discussion, et des entrevues étaient employés afin d'obtenir les perspectives de multiples parties prenantes. Ensuite, des initiatives de renforcement de capacité et des consultations sur les besoins de jeunes en transition étaient effectuées afin de développer un inventaire de préparation à la transition. Nous discutons de l'importance d'impliquer les jeunes comme collaborateurs et comme répondants, ainsi que des processus d'adaptation aux contextes locaux d'implantation.

Mots clés : usage de substances, système de services, engagement des jeunes, collaboration intersectorielle, équité en santé, échange de connaissances

Although experimenting with substances is common, rates of substance use problems increase significantly in adolescence and emerging adulthood (e.g., Boak, Hamilton, Adlaf, \& Mann, 2015). Problematic substance use can have long term impacts for youth, and is often complicated by co-occurring mental health concerns, increasing the risk for negative health and life outcomes (Grella, Hser, Joshi, \& Rounds-Bryant, 2001; Roberts, Roberts, \& Xing, 2007; Storr, Pacek, \& Martins, 2012; Vida et al., 2009). Adolescence and emerging adulthood are challenging periods of transition and change; unmet need for mental health and substance use services can interfere with developmentally salient domains including education, work, and relationships (Goodman, Henderson, Peterson-Badali, \& Goldstein, 2015; MacLeod \& Brownlie, 2014). The continuing low rate of treatment for mental health concerns among children and youth (Auditor General of Ontario, 2008) is just one indicator of the need for system enhancement addressing child and youth mental health difficulties including substance use concerns (Mohajer \& Earnest, 2009).

A consistent message in Changing Direction, Changing Lives: The Mental Health Strategy for Canada is the need to increase the extent to which services are designed and reviewed by the people who use them (Mental Health Commission of Canada, 2012). Youth perspectives are critical if services are to be developmentally informed and responsive to the differences in the needs of youth with mental health and substance use concerns in comparison with those of adults (e.g., Goodman et al., 2015; Wagner, 2008). For example, youth often lack financial independence, autonomy, and stability in various life domains, including social determinants of health such as housing. Further, socio-emotional needs and vulnerability to abuse and other 
traumas are typically greater for youth than for adults (Stanis \& Andersen, 2014). As well, youth tend to be involved in multiple service sectors and may not access mental health or substance use systems directly (Garland et al., 2001; Gilbert et al., 2009); rather, they may seek help or support (or appear in distress and receive help or support) from school guidance counsellors, coaches, shelter workers, and others whose paths they cross who may not have training or resources to identify or respond to youth needs in these areas.

It is important to note that the needs and social contexts of early to mid-adolescents are often different from those of transition-aged youth. Service contexts also differ as older youth are often required to transition to adult services (Watson, Carter, \& Manion, 2014). In addition, implementation of service enhancements must be tailored to local communities (Mental Health Commission of Canada, 2012). This is especially relevant for youth who are disproportionately impacted by local contexts, such as educational and recreational programming and availability of public transportation (Pullmann et al., 2013) Thus, ongoing collaboration and consultation is required that includes the perspectives of local youth as well as other local stakeholders.

The rationale for inclusion of youth perspectives to ensure accurate representation of their unique needs is clear (Mental Health Commission of Canada, 2012). The social and service contexts for youth, particularly younger youth, are unique and bring ethical and social challenges that must be considered. There may be reporting obligations and consequences related to identification of substance use concerns, and treatmentseeking that could impact service access, as well as education, child welfare, and justice system involvement for youth and/or their care providers. Inviting youth perspectives from youth who have had experience of, or are involved in, "mandated" services requires particular attention to these challenges and clarity regarding ethics, safety, confidentiality, and respect.

This spotlight paper describes the Youth Services System Review, a project aimed at improving youth services addressing substance use in Ontario. We describe the project design, summarize key findings, and discuss the key collaborations that were central to the project. We discuss (a) the important role of youth as collaborators as well as respondents, and (b) the processes used to tailor findings to local contexts, in moving from consultation to implementation of system enhancements recommended in the review.

\section{The Youth Services System Review: Overview}

The Youth Services System Review (YSSR) is a two-phase project completed from 2011 to 2014 funded under Health Canada's Drug Treatment Funding Program (DTFP) with the aim of enhancing the youth service system to better meet the needs of youth. The project was created in the context of concerns raised over inadequate system response to the substance use treatment needs of youth, including services addressing concurrent substance use and mental health disorders.

Briefly, YSSR Phase 1 (information gathering) was a review of services addressing substance use available to youth in Ontario which was designed to identify gaps and opportunities for collaboration in order to better meet youth needs. YSSR Phase 2 (implementation in local communities) consisted of capacity building and knowledge translation and exchange (CB-KTE) events to facilitate system change and enhancement in local communities, based on local prioritization of the recommendations from Phase 1. The CB-KTE activities will be described more fully below. The information gathered in the CB-KTE events was also used in 
the construction of transition-readiness checklists for service providers working with transition-aged youth (Henderson \& Chaim, 2015). An overview of the project is shown in Figure 1.

Figure 1

Overview: Youth Services System Review

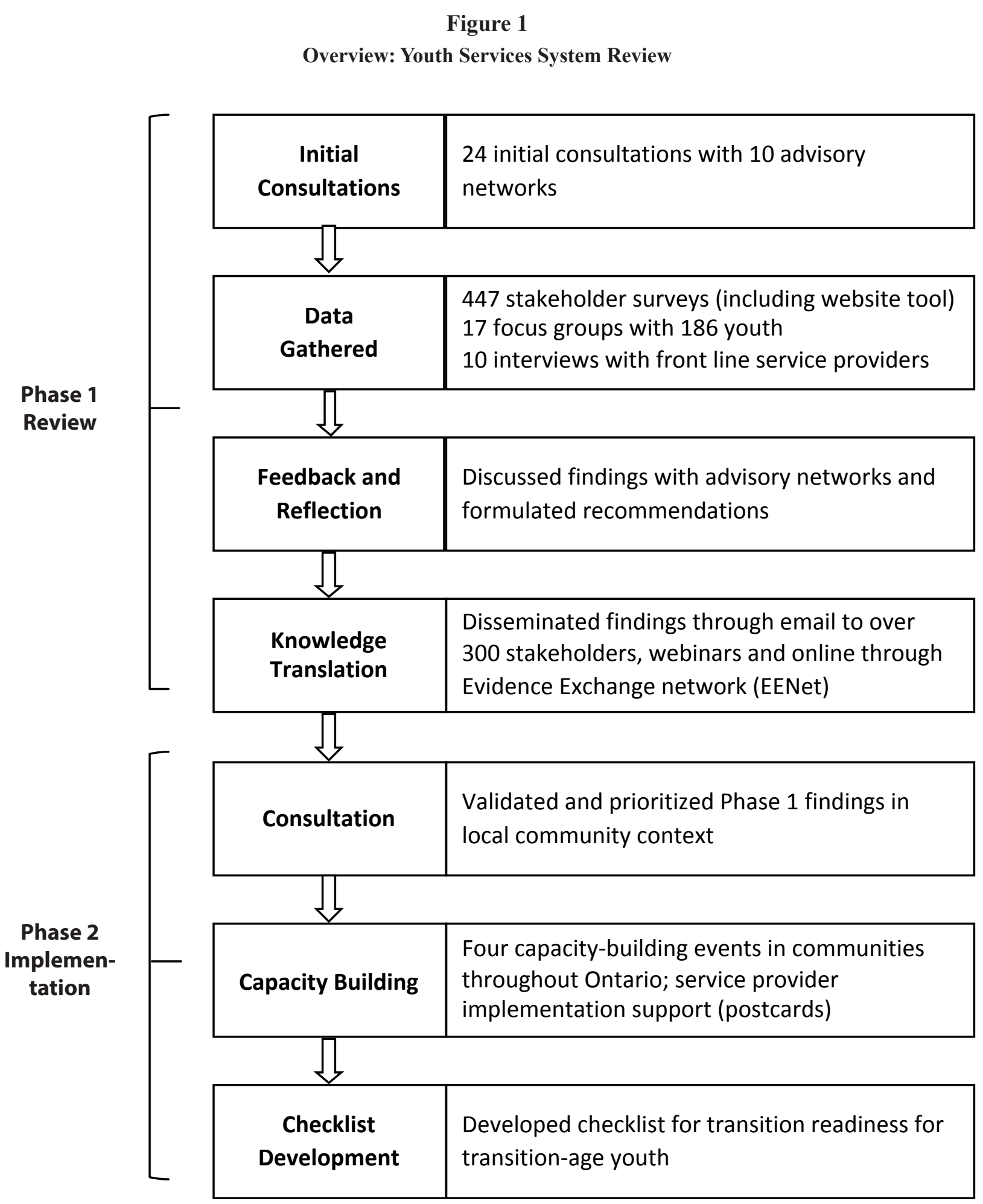


The project was designed using a collaborative model based on the following principles: (1) youth focus, recognizing that youth knowledge and perspectives are crucial to inform system change that will be responsive to youth needs (Narendorf, Fedoravicius, McMillen, McNelly, \& Robinson, 2012); (2) multisectoral approach, including education, child welfare, youth justice, mental health, and other sectors in addition to substance use/addictions, given that youth with mental health and/or substance use concerns are involved in various service sectors (Garland et al., 2001); (3) hearing many voices, including family members/supporters of youth, service providers, and other stakeholders because of the unique information each can provide based on their interactions with the service system (Mental Health Commission of Canada, 2012); and (4) health equity, attending to population-specific needs and to the social determinants of health, which are connected to youth well-being and access to services (Chaim, Henderson, \& Brownlie, 2013; Mental Health Commission of Canada, 2012; Thomée et al., 2016). Additional principles prioritized at Phase 2 were: (5) developmental focus, attending to the needs of younger and older youth and transitions to adult services (Goodman et al., 2015), and (6) tailoring to local context, each of which is essential for implementing developmentally informed system change for youth (Mental Health Commission of Canada, 2012; Henderson, Chaim, \& Brownlie, in press ).

\section{Advisory Structures}

YSSR was guided by 10 pre-existing advisory networks from various sectors that were already working on enhancing youth services and/or enhancing substance use and mental health services, including a panel of people with lived experience of mental health or substance use concerns and family members. Network stakeholders were diverse in sector, discipline, and agency representation.

In addition, at Phase 2 a youth advisory network provided constructive and critical feedback on project design and materials. Two Youth Engagement Facilitators (YEFs; OH and TH) were liaisons between the youth network and the project team; their role is more fully described below.

\section{Phase 1: Information Gathering}

Information was gathered from youth, service providers, family members/supporters of youth and other stakeholders on the perceived strengths and weaknesses of the system of services addressing substance use concerns for Ontario youth aged 12 to 24 (see Table 1). Methods and participants by sector are summarized in Table 2.

Youth-focused website and data collection tool/survey. A website was created with an embedded

data collection tool which was designed to be engaging and accessible to youth. The tool provided options to respond to general or specific questions, or to provide feedback on any aspect of the service system. Thus, youth who did not wish to complete a more lengthy survey could comment on issues important to them. The website was promoted with fliers sent to youth-serving agencies, through social media, and in collaboration with other youth-focused websites and organizations. Paper surveys with parallel questions were made available to youth at conferences, campuses, and youth-serving agencies. The website and surveys were also promoted to networks of service providers and family members/supporters of youth. 


\section{Table 1}

\section{Stakeholder Participation}

\begin{tabular}{lcccc}
\hline & Youth & Family & $\begin{array}{c}\text { Service } \\
\text { Providers }\end{array}$ & $\begin{array}{c}\text { Other } \\
\text { Stakeholders }\end{array}$ \\
\hline Phase 1 & & & & \\
$\quad$ Focus group participants (17 focus groups) & 186 & & & \\
$\quad$ Web-based and paper survey respondents & 116 & 23 & 263 & 45 \\
$\quad$ Interviewees & & & 10 & \\
Phase 2 & 11 & 3 & 168 \\
$\quad$ Capacity building/consultation participants & & & \\
\hline
\end{tabular}

Note. Service providers who were also youth and/or family members of youth with mental health or substance use concerns were included in the service provider group only.

To promote the website/survey, a database of Ontario youth-serving agencies across sectors was constructed based on information provided by ConnexOntario, community liaisons from the Centre for Addiction and Mental Health's Provincial System Support Program (PSSP), the project's advisory networks, and from internet searches. In order to reach youth not engaged in traditional services, attempts were made to identify informal services addressing youth substance use that may be "under the radar" of the funded youth substance use service system. Systematic efforts were made to identify where youth may be accessing such assistance, by asking all stakeholders, particularly youth, where youth might access such services in their local community.

Focus groups. Focus groups were conducted to gather more contextualized and detailed information from youth. Nine focus groups were held in youth substance use/addictions services and mental health agencies $(n=108)$. The remaining nine groups $(n=78)$ were held in drop-in centres, child welfare and youth justice agencies, youth engagement/advocacy sectors and other community agencies. Participation was voluntary and youth were encouraged to report on their perspectives based on the experiences of themselves or others they knew without needing to disclose or identify their own experiences. Approximately equal numbers of adolescents $(n=91)$ and emerging adults over age $18(n=92)$ participated. Most youth were currently using services addressing substance abuse $(n=96 ; 67 \%)$ or had previously used services $(n=24 ; 17 \%)$. Three $(2 \%)$ reported they wanted to but were unable to access services and $25(17 \%)$ reported they were not interested in using services.

Interviews. Detailed interviews were conducted with 10 service providers from various service sectors.

\section{YSSR Phase 2: Implementation/Consultation in Local Communities}

In order to maximize local engagement, the project team collaborated with the community liaison team to identify communities interested in participating in piloting a capacity-building and knowledge translation and exchange (CB-KTE) event. The CB-KTE events were promoted via local youth-serving and adult-serving 


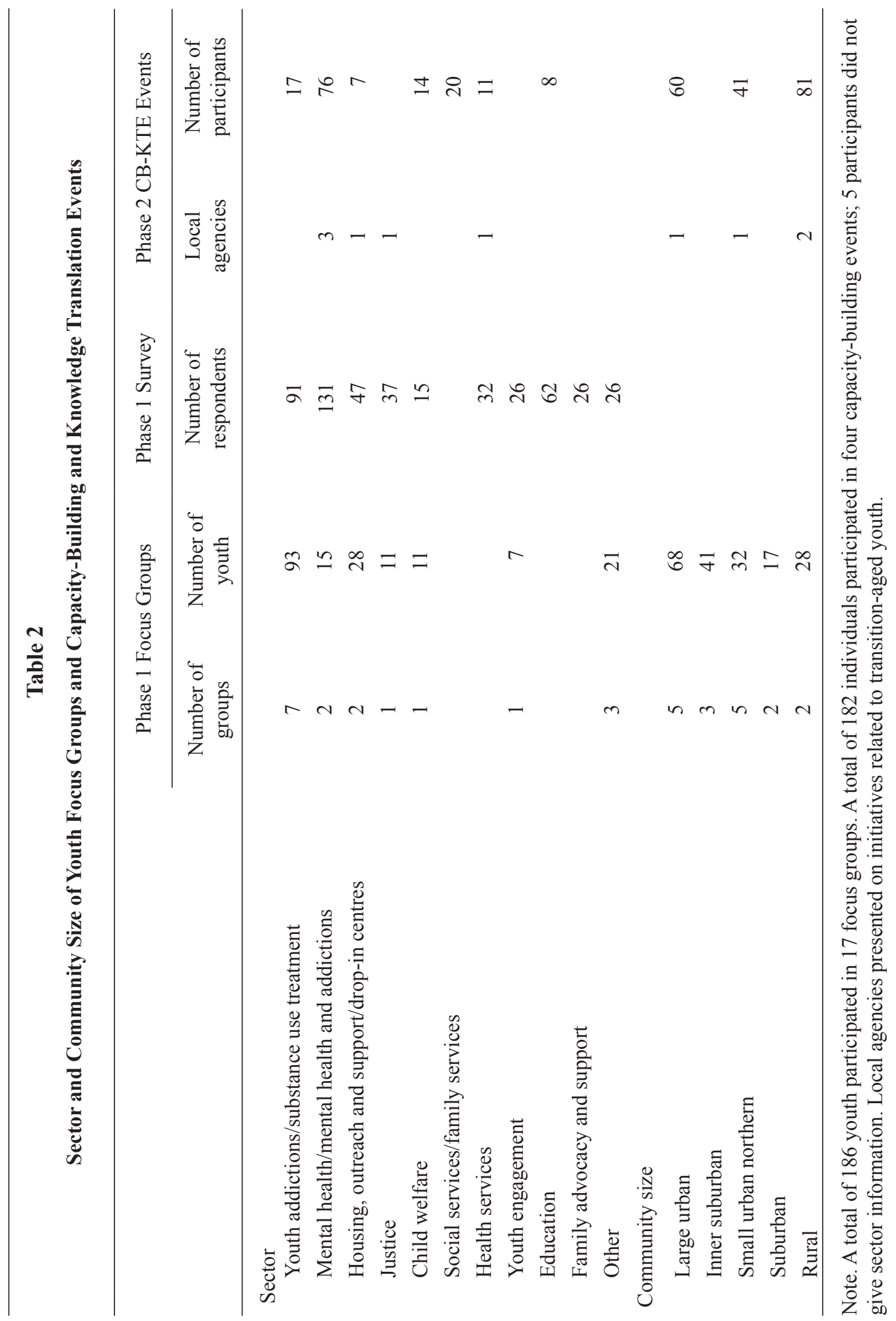


agencies and community network listservs, in committee meetings, and via service providers, agencies, and networks working on enhancing services for transition-aged youth.

Four CB-KTE events were delivered collaboratively with YEFs and project leads in communities across Ontario, including urban, rural, and northern communities. The events, entitled Let's Talk: A conversation about developmentally-informed care and enhancing services for transition-aged youth, had the following objectives: (1) learn about, and discuss the needs of, adolescents and young adults, and consider feasible, cross-sectoral, developmentally informed service responses; (2) discuss the current state of local services for transition-aged youth and cross-sectoral collaboration amongst youth-serving and adult-serving providers, and potential for enhancement in their communities; (3) develop actionable recommendations for implementation at the individual, agency, and community level; and (4) inform a report to be widely shared with youth, families, service providers, communities, policy makers, and government. The CB-KTE events were attended by youth, family members, and service providers from six sectors and from the youth and adult service systems (see Tables 1 and 2).

Knowledge translation and exchange. Knowledge translation and exchange activities at the CB-KTE events included (1) sharing and discussion of findings from Phase 1 (Chaim et al., 2013) and from related projects on collaboration and youth services (Henderson et al., in press); (2) an overview of child/youth development and the impacts of substance use and mental health problems; (3) opportunities and challenges of emerging adulthood, (4) local examples of initiatives addressing the needs of transition-aged youth and (5) an international example, the Transition to Independence model (Clark \& Unruh, 2009).

Local context: ecosystem maps. Prior to each CB-KTE event, an ecosystem map was developed for each community to provide a context to situate the conversation. The ecosystem maps provided a visual representation of the local service system including services, initiatives, and networks addressing youth substance use and mental health concerns at local, as well as provincial and national levels. An example is shown in Figure 2. The community liaisons facilitated the development of the maps, and presented and facilitated discussion of the maps at the CB-KTE events. As noted above, representatives from local initiatives related to transition-aged youth were invited to share information about their projects.

Consultation: Developmentally specific needs. In small groups, participants identified needs of youth in specific age categories (12-15, 16-18 and 18-24), and needs applicable across the age groups. Responses were compiled and discussed in the reassembled large group, with discussion led by YEFs.

Consultation: Youth transition-readiness checklists. In small groups, participants discussed: (1) what youth-serving providers need to do to prepare youth for transition to adult services, and (2) what adult-serving service providers need to do to engage and work effectively with transition-aged youth. Ideas were recorded and debriefed with the larger group, with YEFs facilitating the discussion to maintain the focus on youth experiences. The discussions were synthesized and informed the development of checklists for use by service providers across Ontario from both youth-serving and adult-serving agencies (Henderson \& Chaim, 2015).

Commitment postcards facilitating change. As a means of transforming knowledge from the CB-KTE event into concrete action, participants were asked to record on a postcard a change they were prepared to make following the workshop to impact service delivery at individual, agency, and community levels. Each 
Figure 2

Example of Local Ecosystem Map

\section{THE ECOSYSTEM OF INITIATIVES RELATED TO YOUTH MENTAL HEALTH AND ADDICTIONS IN HASTINGS \& PRINCE EDWARD COUNTIES}

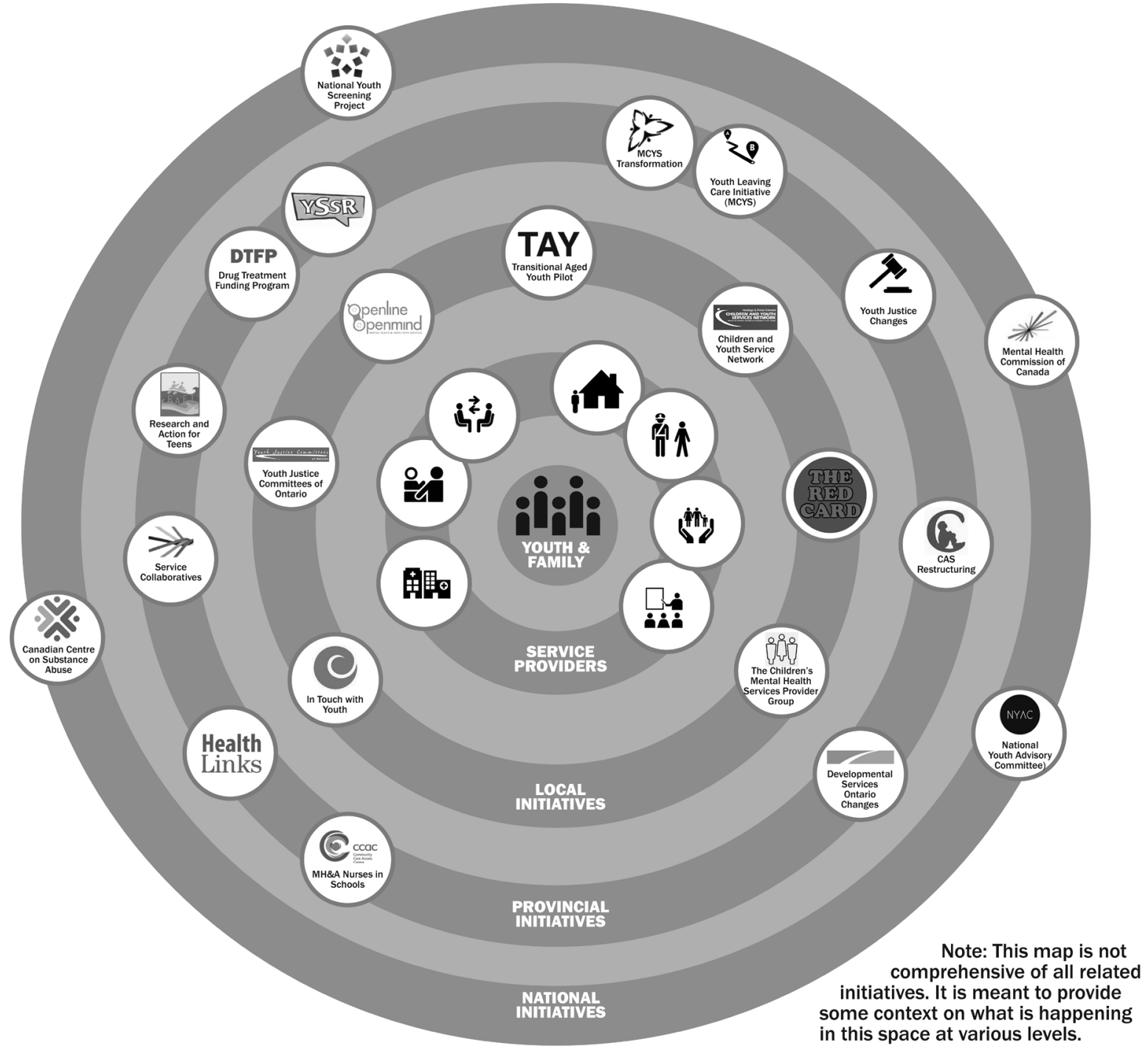


participant's postcard was mailed to them one month after the event to serve as a reminder and motivator to act on their commitments; for privacy reasons, postcards were not reviewed by YSSR staff.

\section{Summary of Findings}

Table 3 summarizes the problems and suggestions identified by participants in YSSR Phases 1 and 2, including age-specific issues identified in CB-KTE events at Phase 2. At Phase 1, there was a consensus among service providers, youth, and family members that access to services addressing substance use is a continuing problem. Perceived lack of availability of services, particularly in non-urban areas of the province, low awareness by youth of the services available, numerous practical barriers to accessing services, and poor coordination were frequently mentioned. The need for accessible, developmentally informed services across the continuum of care, with well-trained, engaging, caring staff to meet the diverse needs of youth with varied backgrounds and experiences was commonly endorsed.

Some findings were more specific to stakeholder groups. In Phase 1 focus groups, youth described difficulties accessing services due to barriers such as transportation, and also emphasized the importance of youth-friendly services that are appealing and unintimidating, accessible, with evening hours, and staffed with service providers who are non-judgmental, respect confidentiality, and are relatable to youth. They also highlighted the importance of these latter factors due to the fear some youth experience when seeking services given the stigma associated with youth substance use as well as mental health concerns. Although they were not asked to comment on their own services, service providers noted the importance of, and need for, increased implementation of evidence-informed services and standards of care across the youth service system. Family members/supporters of youth described difficulties in navigating the service system with, or on behalf of youth, and emphasized the need for support services for family members and others supporting youth. Additional issues identified were the need for services across the continuum of care, various service and service provider attributes, and the need for attention to health equity and the social determinants of health. In addition, service delivery models were identified as needing considerable attention, particularly increased coordination and collaboration. The need for system improvements in services for transition-aged youth and collaboration with the adult sector for smoother transitions was emphasized.

The majority of Phase 1 findings were endorsed at Phase 2 in the local community contexts; however, there were differences in priorities among communities. In addition, age-specific issues were identified. For older youth, several suggestions were given including smoother transitions to adult services and flexible service delivery (e.g., walk-in formats) and attention to developmentally salient tasks (e.g., support for vocational development). For youth under 16, suggestions included school-based interventions and coordination, respect for confidentiality, opportunities for caregiver involvement if desired, and services for parents/caregivers.

\section{Implementation Survey Results}

Phase 2 CB-KTE event participants were invited to participate in a follow-up survey approximately six weeks after the event. Over one-third (38\%) of service provider participants completed the survey $(n=64)$. Respondents reported that they worked with youth (41\%), youth and adults (45\%), or adults only (7\%). Respondents typically reported that the event had changed their knowledge or attitudes about developmentally 


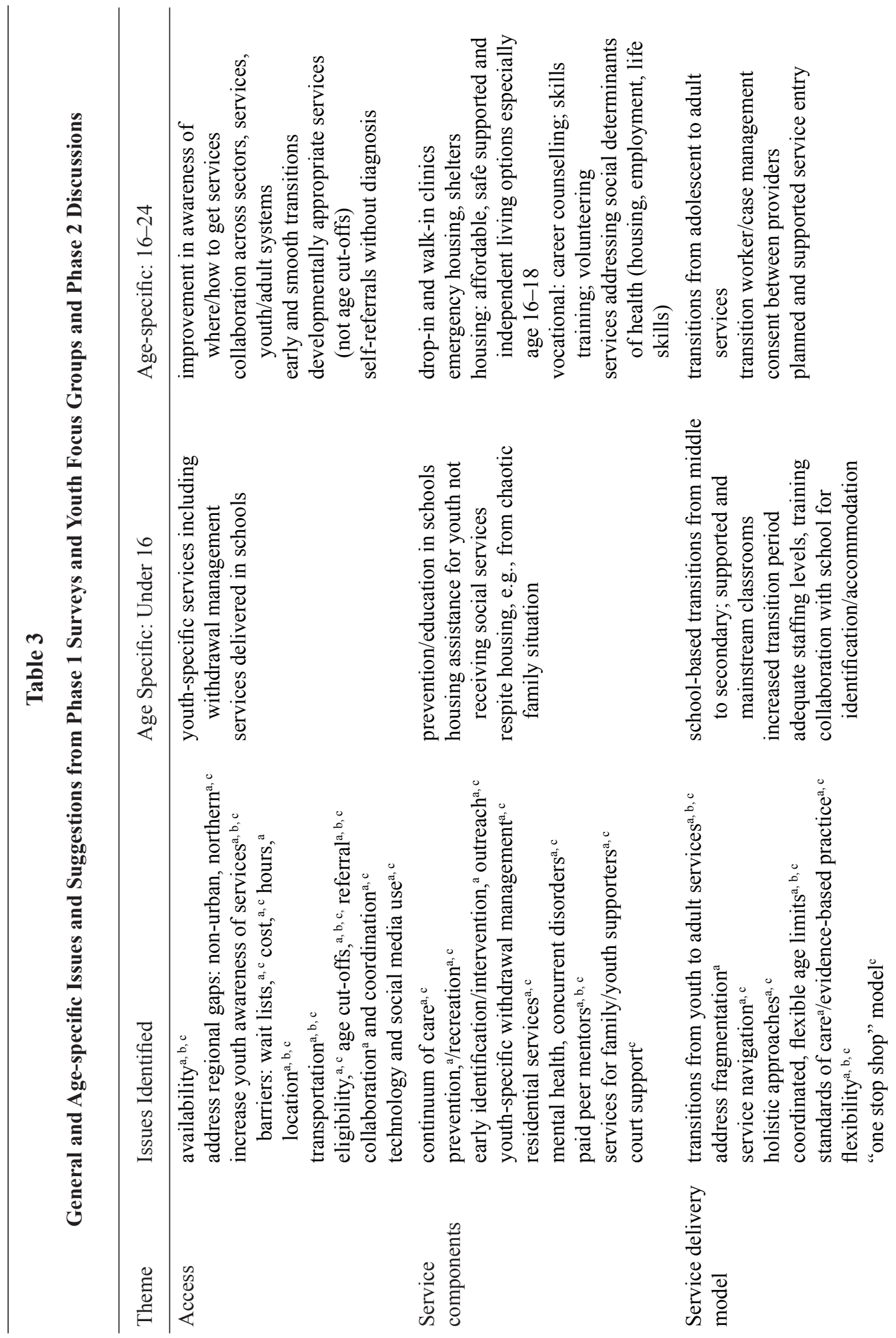




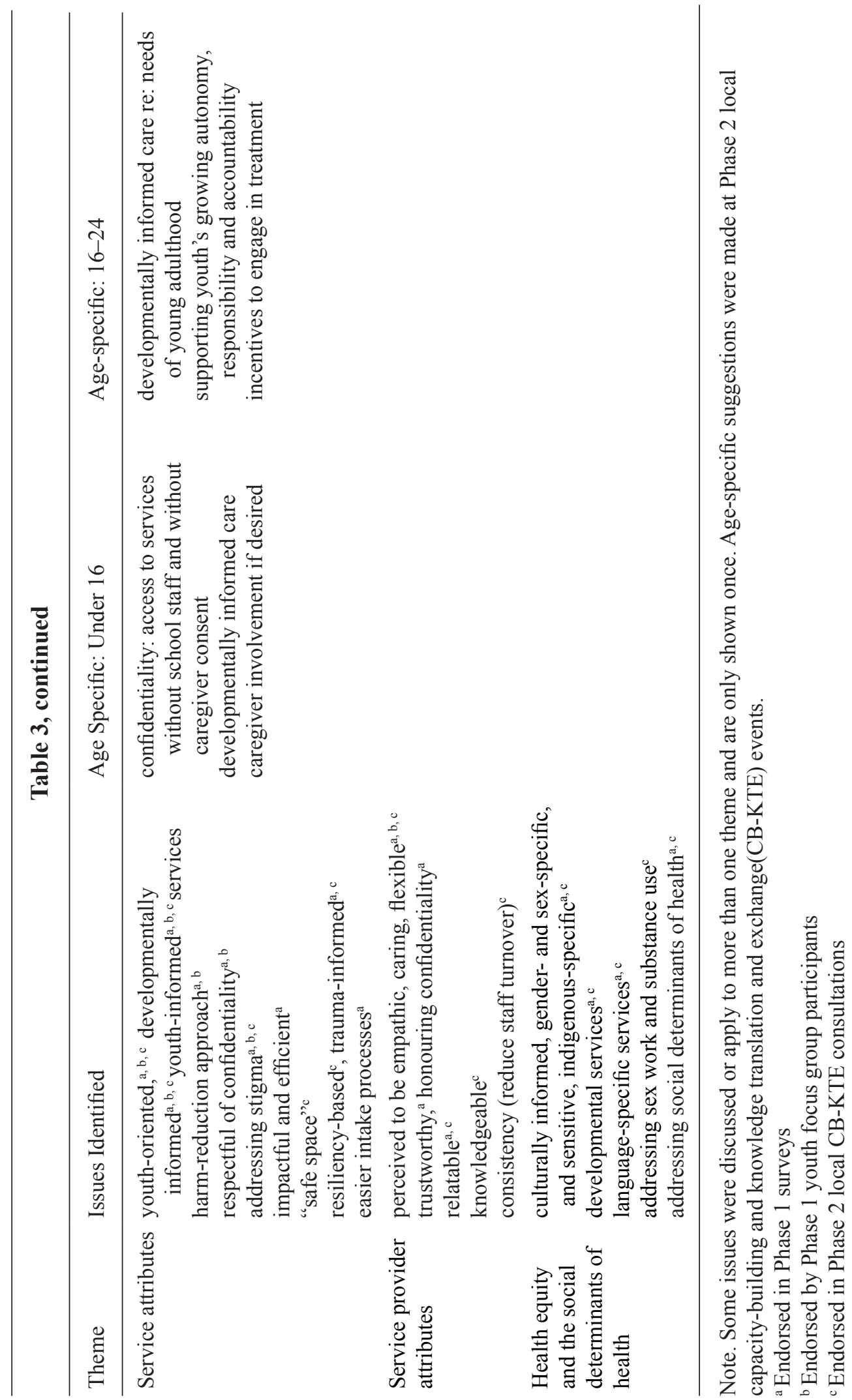


informed care and ways that services for transition-aged youth can be enhanced (77\%), and that they had communicated with colleagues about the workshop discussions (93\%). Sixty-four percent of respondents reported that they participated in the postcard implementation reminder; $83 \%$ of these reported they were currently working on implementing their change. When asked which factors would facilitate vs. impede implementation of this change, respondents endorsed collaboration with colleagues (50\%), knowledge gained from the workshop (42\%), creation of an action plan (29\%), formal or informal reflection (29\%), and creation of reminders/deadlines (25\%) as facilitators, and limitations in time (37\%), funding (16\%), staffing (16\%), and organizational support (8\%) as barriers.

\section{DISCUSSION}

Youth substance use and mental health services are impacted by general under-resourcing, compounded by the relative neglect of child and youth mental health compared with adult mental health (Mental Health Commission of Canada, 2012), and by the stigma associated with substance use as well as mental health difficulties, particularly among youth (Clement et al., 2015; Pullmann et al., 2013). Additionally, longstanding systems challenges include the need for coordination across multiple sectors and the need to address transitions from youth to adult services (Garland et al., 2001; Watson et al., 2014). A developmentally informed, effective, and engaging service system must be informed by youth perspectives and relevant to local conditions and contexts (Pullmann et al., 2013).

\section{Importance of Youth Engagement}

The input of youth is crucial to inform the design of services that will be appropriate and effective in meeting the needs of youth. Although the importance of youth involvement in informing and implementing system change is acknowledged (e.g., Cheung, Dewa, Cairney, Veldhuizen, \& Schaffer, 2009; Watson et al., 2014), a greater challenge is to insure that engagement is meaningful, responsive, and empowering to youth (Pullmann et al., 2013). This project demonstrated the exponential value added from youth involvement as collaborators and co-creators in efforts to further youth service system change.

At Phase 1, youth were involved in facilitating focus groups, collecting data, and contributing to the design of the youth-focused website and other project communications. Further, the project was designed to be engaging to youth and to reach diverse youth constituencies to maximize the number and breadth of youth responses. At Phase 2, youth involvement was expanded. In particular, the two YEFs were integral members of the project team, contributed to project design and development of the CB-KTE events, led consultations with the youth advisory network, and ensured the relatability of project content. As well, they played central roles in the CB-KTE events, where they engaged, supported, and encouraged the participation of youth participants; foregrounded youth perspectives in discussions, bringing in their own and other youths' experiences; and maintained a supportive and safe environment for discussions. In evaluations, event participants frequently noted how important the YEFs were in grounding discussions in real world contexts. The YEFs also contributed to data analysis and interpretation, informed by their own experiences and the perspectives of other youth participants. The extent of youth participation and the alignment of youth and 
other stakeholder perspectives in many domains counter narratives which suggest that youth do not know what they want or need, or have unreasonable expectations.

There are challenges in fully involving youth in mixed groups with youth and adult stakeholders, given inherent power differentials that are exacerbated when youth are outnumbered. These challenges can be addressed in various ways, such as including separate groups for youth and adults, and increasing efforts to create a more equal number of participants representing different stakeholder groups. In this project, the capacities, preferences, and needs of youth participants varied; whereas some youth were comfortable joining the broader discussion groups without facilitation, others required more support and engagement. Youth also varied in whether they preferred a separate "youth table." Thus, it may be helpful to provide options for various types of engagement, with flexibility in the level of support and facilitation provided. Nevertheless, although separate, youth-specific groups may address some challenges, the integration of YEFs in the project planning team was integral to the success of the project. The participation of the YEFs at the CB-KTE events was also beneficial in modelling to other youth how to participate and discuss their own experiences in a safe and effective manner. Finally, the importance of providing youth with as much information as possible in advance of events on what to expect, including material to be covered and practical details such as dress code, was learned over the course of the project.

\section{Tailoring to Local Communities}

Moving from data gathering to implementation, the Phase 2 project took steps to increase applicability to the local community context. The CB-KTE events were planned collaboratively with community liaisons familiar with local service systems. Stakeholders and organizations were identified and invited to participate. Presentations of local initiatives by local providers, and the use of local ecosystem maps, ensured that the discussion reflected local strengths and priorities. In addition, province-wide findings from Phase 1 were discussed in light of local community needs and contexts. As well, reflection and planning checklists for continued service enhancement were developed at the CB-KTE events based on distinct community contexts. These checklists can be shared and implemented in participating communities and beyond. This is an example of the continuing benefit of combining knowledge exchange and implementation in local community contexts. For some groups, including First Nations, Inuit, and Métis communities, separate processes would be important with leadership and involvement in those processes by the communities throughout (Mental Health Commission of Canada, 2012).

\section{Collaborations for System Change}

This project also illustrates the feasibility and value of collaborative processes in informing and implementing system change. Multiple existing networks participated in informing the design. This included the youth advisory network, which had been assembled to consult on multiple projects. As a result, there were relatively few demands placed on participating groups, and a wide variety of feedback enhanced engagement with various stakeholders.

An additional implementation component at Phase 2 was the strengthening of system capacity though collaborations and relationships formed or enhanced through the CB-KTE events. Opportunities to meet to 
talk about how an effective system can be built, where stakeholders can consider what they can contribute within their current mandates and constraints, and what they can lobby for and do differently, facilitate creative ideas and strengthen implementation efforts. Notably, almost all participants responding to the post CB-KTE event survey reported having discussed the event with colleagues. Further, in post-event surveys, service providers most frequently listed collaboration with colleagues as a facilitator of implementation of system change. Broader implementation of the transition-readiness checklists also has the potential for enhancing further collaborations. It is essential that we find ways to facilitate ongoing dialogue, not only at a system level, but also at individual, service, and agency levels.

The project also underscores the importance of collaboration among stakeholder groups, beyond service providers, with different roles, perspectives, expertise, and opinions. Most importantly, hearing from, and listening to, the stakeholders who are the focus of service - youth - to understand what they want, need, and find engaging is crucial. It is also essential to seek input from family members and other youth supporters, who engage with the youth services system sometimes more extensively than youth themselves, both in locating and navigating youth services and seeking services for themselves.

A challenge in working on youth system enhancement is the complexity of the service system given the multiple sectors involved. A related challenge is working across youth and adult systems. Multiple cross-sectoral youth- and adult-serving agencies participated in hosting focus groups and CB-KTE events and facilitated implementation by connecting the project to their local contexts. Involving adult-focused services and providers requires clear communication on the importance of developmentally informed care and the unique needs of youth for their younger clients. Conversely, lack of knowledge on the importance of developmentally informed care can result in low engagement and little interest in participation in collaboration with youth among some adult services.

This project illustrates some of the benefits and challenges of collaboration toward the goal of system enhancement. Although attempts were made to be inclusive, not all voices were heard, in part due to project constraints in the number and capacity of groups and events as well as challenges inherent in reaching individuals and groups representative of the breadth of intersectionality across communities. As well, since youth services and online resources were used to engage youth and families, those least engaged in services and those not having access to internet were likely unrepresented. In addition, although Phase 1 survey responses were compiled, and focus group and interviews were recorded, transcribed, and coded, recording was more difficult in the live discussions at the CB-KTE events; therefore some contributions may have been missed. Finally, although the focus of this article is youth services, many of the lessons learned are likely applicable to services for other age groups.

In conclusion, the YSSR project suggests that with support, youth, family members, service providers, and other stakeholders are eager to come together to have meaningful dialogue and consider new ways of collaborating to foster system change. The results of the project underscore the feasibility and value of promoting system enhancement by gathering feedback and recommendations from key stakeholder groups, attending to areas of overlap as well as perspectives specific to stakeholder groups. Stakeholder-specific perspectives are essential in informing service delivery that is engaging to youth, useable by families and youth supporters, and effective. Nevertheless, the high level of agreement across groups regarding many of the recommended system enhancements suggests there may be broad support for their implementation. 


\section{REFERENCES}

Auditor General of Ontario. (2008). Annual Report of the Auditor General of Ontario, 2008. Retrieved from http:// www.auditor.on.ca/en/content/annualreports/arbyyear/ar2008.html

Boak, A., Hamilton, H. A., Adlaf, E. M., \& Mann, R. E. (2015). Drug use among Ontario students, 1977-2015: Detailed OSDUHS findings (CAMH Research Document Series No. 41). Toronto, ON: Centre for Addiction and Mental Health.

Chaim, G. C., Henderson, J. L., \& Brownlie, E. B. (2013). Youth services system review. Toronto: authors. Retrieved from http://eenet.ca/dtfp/youth-services-system-review-project/, accessed April 27, 2016.

Cheung, A., Dewa, C., Cairney, J., Veldhuizen, S., \& Schaffer, A. (2009). Factors associated with use of mental health services for depressed and/or suicidal youth aged 15-24. Community Mental Health Journal, 45, 300-306. doi:10.1007/s10597-009-9205-8

Clark, H. B., \& Unruh, D. K. (2009). Transition of Youth and Young Adults with Emotional or Behavioral Difficulties: An Evidence-Supported Handbook. Baltimore, MD: Brookes Publishing Company.

Clement, S., Schauman, O., Graham, T., Maggioni, F., Evans-Lacko, S., Bezborodovs, N., ... Thornicroft, G. (2015). What is the impact of mental health-related stigma on help-seeking? A systematic review of quantitative and qualitative studies. Psychological Medicine, 45(1), 11-27.

Grella, C. E., Hser, Y., Joshi, V., \& Rounds-Bryant, J. (2001). Drug treatment outcomes for adolescents with comorbid mental and substance use disorders. The Journal of Nervous and Mental Disease, 189, 384-392. doi:10.1097/00004583-200104000-00009

Garland, A. F., Hough, R. L., McCabe, K. M., Yeh, M., Wood, P. A., \& Aarons, G. A. (2001). Prevalence of psychiatric disorders in youths across five sectors of care. Journal of the American Academy of Child \& Adolescent Psychiatry, 40, 409-418.

Gilbert, R., Spatz Widom, C., Browne, K., Fergusson, D., Webb, E., \& Janson, S. (2009). Burden and consequences of child maltreatment in high-income countries. The Lancet, 373, 68-81. doi:10.1016/S0140-6736(08)61706-7

Goodman, I., Henderson, J., Peterson-Badali, M., \& Goldstein, A. L. (2015). The relationship between psychosocial features of emerging adulthood and substance use change motivation in youth. Journal of Substance Abuse Treatment, 52, 58-66. doi:10.1016/j.jsat.2014.12.004

Henderson, J. L., \& Chaim, G. C. (2015). Optimizing services for transitional-aged youth. Toronto: Authors.

Henderson, J. L., Chaim, G. C., \& Brownlie, E. B. (in press). Collaborating with community-based services to promote evidence-based practice: Process description of a national initiative to improve services for youth with mental health and substance use problems. Psychological Services.

MacLeod, K. B., \& Brownlie, E. B. (2014). Mental health and transitions from adolescence to emerging adulthood: developmental and diversity considerations. Canadian Journal of Community Mental Health, 33, 77-86. doi:10.7870/cjemh-2014-007

Mental Health Commission of Canada. (2012). Changing directions, changing lives: The mental health strategy for Canada. Calgary, AB: Author.

Mohajer, N., \& Earnest, J. (2009). Youth empowerment for the most vulnerable: A model based on the pedagogy of Freire and experiences in the field. Health Education, 109, 424-438. doi:10.1108/09654280910984834

Narendorf, S. C., Fedoravicius, N., McMillen, J. C., McNelly, D., \& Robinson, D. R. (2012). Stepping down and stepping in: Youth's perspectives on making the transition from residential treatment to treatment foster care. Children and Youth Services Review, 34, 43-49. doi:10.1016/j.childyouth.2011.08.031

Pullmann, M., Ague, S., Johnson, T., Lane, S., Beaver, K., Jetton, E., \& Rund, E. (2013). Defining engagement in adolescent substance abuse treatment. American Journal of Community Psychology, 52, 347-358. doi:10.1007/ s10464-013-9600-8

Roberts, R. E., Roberts, C. R., \& Xing, Y. (2007). Comorbidity of substance use disorders and other psychiatric disorders among adolescents: Evidence from an epidemiologic survey. Drug and Alcohol Dependence, 88, S4-S13. doi:10.1016/j.drugalcdep.2006.12.010

Stanis, J. J., \& Andersen, S. L. (2014). Reducing substance use during adolescence: A translational framework for prevention. Psychopharmacology, 231, 1437-1453. doi:10.1007/s00213-013-3393-1 
Storr, C. L., Pacek, L. R., \& Martins, S. S. (2012). Substance use disorders and adolescent psychopathology. Public Health Reviews, 34, 1-42.

Thomée, S., Malm, D., Christianson, M., Hurtig, A., Wiklund, M., Waenerlund, A., \& Goicolea, I. (2016). Challenges and strategies for sustaining youth-friendly health services-A qualitative study from the perspective of professionals at youth clinics in northern Sweden. Reproductive Health, 13, 147. doi:10.1186/s12978-016-0261-6

Vida, R., Brownlie, E. B., Beitchman, J. H., Adlaf, E. M., Atkinson, L., Escobar, M., ... Bender, D. (2009). Emerging adult outcomes of adolescent psychiatric and substance use disorders. Addictive Behaviors, 34, 800-805. doi:10.1016/j.addbeh.2009.03.035

Wagner, E. F. (2008). Developmentally informed research on the effectiveness of clinical trials: A primer for assessing how developmental issues may influence treatment responses among adolescents with alcohol use problems. Pediatrics, 121 Suppl 4, S337-S347. doi:10.1542/peds.2007-2243F

Watson, G., Carter, C., \& Manion, I. (2014). Pathways to care for youth with concurrent mental health and substance use disorders. Ottawa: Ontario Centre of Excellence for Child and Youth Mental Health. 